\title{
Finite Element Analysis on Seismic Behavior of Embedded Self-Centering Rocking Wall Structure
}

\author{
Qin Peiyuana, Wu Hanheng, Wu Aizhen \\ School of civil engineering, Chang'an University, Xi'an 710061, Shaanxi, China
}

Keywords: Self-Centering Rocking Wall, Steel Frame, Seismic behavior, Connection methods and structure relations, Finite element analysis

\begin{abstract}
This paper designed a new structure in order to reduce the seismic damage to buildings. In this paper, basic elements, connection methods and structure relations of the selfcentering rocking wall structure were introduced. A series of characteristics, such as high prefabrication degree, replaceable energy dissipation elements, plastic deformation is concentrated in the energy dissipation elements in the earthquake, the lateral resistance system can be arranged convenient and flexible, etc. And the finite element simulation of simplified single frame embedded self-centering rocking wall structure, study on the seismic behavior, the result shows that the structure has good load capacity, energy dissipation and self-centering capacity. So, this new structure can effectively reduce the damage of the earthquake on the buildings.
\end{abstract}

\section{Introduction}

The collapse of buildings in the earthquake caused great loss of life and property, in which the damage caused by the deformation of buildings after the earthquake was too large to be strengthened or removed. Therefore, in recent years, it has become a hot topic in domestic and foreign scholars to study the functional structure of the restoration, which can be continued to be used after the earthquake, and the self-centering structure and the rocking structure are all belong to this structure ${ }^{[1]}$.

At present, there are a lot of researches about self-centering rocking wall. In 1999, Y Kurama studyed on the unbonded prestressed concrete self-centering wall system, the results show that the wall has a very good seismic performance, showing good self-centering performance ${ }^{[2]}$. In 2000, Y Kurama also proposed some improvement measures to improve the energy dissipation capacity of the self-centering wall before the experiment, adding the fluid viscous dampers to the self-centering wall to improve its energy dissipation performance ${ }^{[3]}$. In 2014 , Lv Xilin put forward the self- centering shear walls with horizontal bottom slit structure, through the experimental study and numerical simulation, the result shows that the wall can reduce the residual deformation of the wall and increase the energy dissipation capacity without reducing the bearing capacity and the stiffness ${ }^{[4]}$.

It is worth noticing that the above researches involve the self-centering rocking walls are the cantilever wall, and the actual walls in frame structure are embedded in the frame. Therefore, this paper, based on the previous research methods, describes the basic structure and the connection structure of the embedded self-centering rocking wall structure (hereinafter, ESW), and analyzes

${ }^{\mathrm{a}}$ Qin Peiyuan, 2014228008@chd.edu.cn 
the mechanics phenomena, hysteretic curves, skeleton curves, bearing capacity and deformation properties by finite element simulation.

\section{Introduction of ESW structure}

\subsection{Basic composition}

ESW structure is composed of steel frame, precast concrete self-centering rocking wall, posttensioned steel strands and energy dissipation element, all these are shown in Fig. 1.

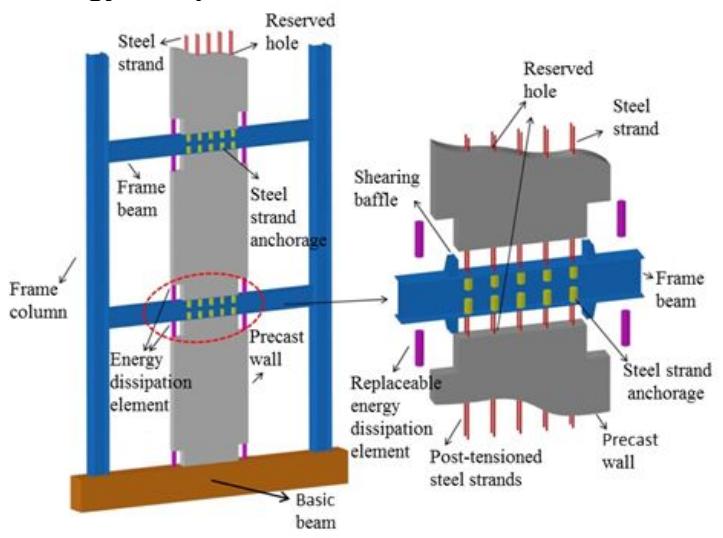

Figure 1. Schematic diagram of the basic structure of ESW structure

\subsection{Connecting structure}

The self-centering wall embedded in the frame, only in contact with the frame beam, but connect with the energy dissipation element by bolts and the energy dissipation element is connected with the frame beam by the same way, details of the structure are shown in Fig.2. The post-tensioned steel strands is arranged in the self-centering rocking wall pore, and anchor in the frame beam, all these are shown in Fig.3.
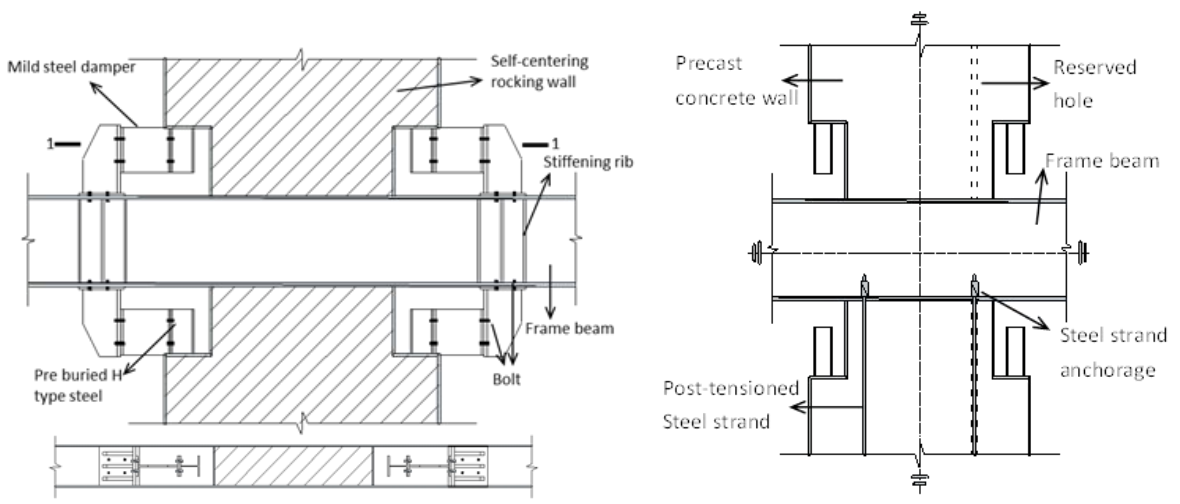

Figure2.. Energy dissipation device connection structure diagram
Figure 3. Post-tensioned steel strand connection structure diagram 


\section{Finite element model of ESW structure}

\subsection{Model introduction}

In this paper, ABAQUS software is used to establish the finite element model of ESW structure. In the model, the steel frame use the simplified model which ignored frame column and only retaining the frame beam. This method can ignore the influence of the frame beam column joints stiffness to energy dissipation properties and self-centering performance of the self-centering rocking wall. The single span single frame model is used as research object, the size of the precast concrete wall is , the strength of concrete is C40, the constitutive relationship is calculated according to the "code for design of concrete structures" GB50010-2010[5]. Top frame beam ,bottom beam ,the strength of steel is Q345. In order to improve the shear strength and local compression performance of the selfcentering rocking wall, the wall is made of steel reinforced concrete wall, the embedded steel with $\mathrm{X}$ shaped cross distribution, the post-tensioned steel strands vertical layout. The application of posttensioned steel strands in the model is realized by "lowering the temperature"[6]. This model the thermal expansion coefficient of the post-tensioned steel strands is . The model diagram as shown in Fig. 4

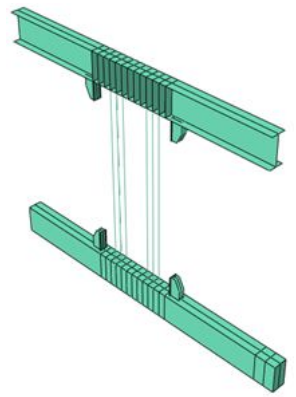

(a)Steel frame and posttensioned steel strand

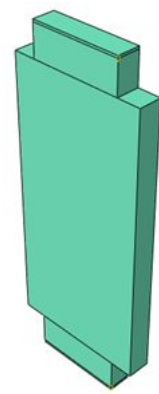

(b)Self-centering rocking wall

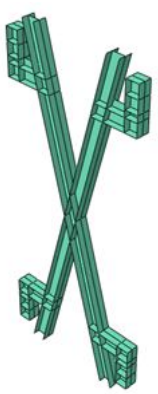

(c)Profiled steel embedded in the wall

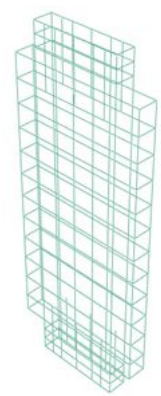

(d) Reinforcing cage

Figure 4. Model diagram

In this paper, the self-centering rocking walls and bottom beam of the steel frame using solid elements (C3D8R) simulation, reinforced and post-tensioned steel strands with the Truss element, built-in type steel and mild steel damper and top beam of steel frame using shell elements (S4R).

\subsection{Contact simulation}

In this paper, the precast concrete wall is in contact with the reinforcing steel bars and the profiled steel, and the influence of the bond slip between the steel bar and concrete is not considered. The bolt connection of the energy dissipation device with the wall and frame beam is simulated by Tie, the connection of the wall and the frame beam is simulated by "surface-to-surface" connect, the normal property of the contact surface is defined as "contact Hard", which is allowed to be separated from the contact surface; the tangential property is defined as Penalty, and the friction coefficient is 0.4 . This approach can be used to simulate the characteristics of the wall corner lifting of the self-centering rocking wall, and it can avoid the concrete tension, so that the structure is more reasonable.

\subsection{Load mode selection}

In this paper, the seismic behavior of the embedded self-centering rocking wall is studied under the cyclic horizontal load which put on the frame beam joint, the value of maximum horizontal displacement of loading point at the end of the beam is , which is the corresponding value of the 
maximum displacement angle of the layers $2 \%$ in the earthquake. The displacement loading system of cyclic horizontal load is shown in Fig 5.

\section{Result analysis}

\subsection{Mechanics analysis}

The model in the loading process through four stages, first, the wall not rotate elastic stage, second, the wall rotate but energy dissipation element is in elastic stage, third, the wall rotation and energy dissipation element began to work to complete yielding stage, fourth, energy dissipation element began to break to complete rupture. The force system, which is composed of the prestress and the wall, resist the bending moment caused by the horizontal load before the self-centering rocking wall begins to rotate, when the wall begins to rotate, the top and bottom diagonal two groups of energy dissipation devices, which have greater force, begin to yield in tension in the first, as the rotation continues to increase, the two groups of energy dissipation devices which are pressed begin to yield, when the wall begins to be unloaded, the energy dissipation device which are in tension is first unloaded to zero and then the energy dissipation device which are pressed unloaded to zero, the wall return to the initial position.

\subsection{Analysis of hysteresis curve and energy dissipation capacity}

The hysteresis curve of the horizontal load - layer displacement angle is shown in Fig.6. In the initial stage of loading, the structure is in a completely elastic stage, so the hysteresis curve is almost a straight line, and the area is very small, the energy dissipation capacity of the mild steel damper is not yet played; With the increase of the load, the rotation angle of the wall increases, the mild steel damper in the corners of the wall begin to yield into the plastic stage, the energy dissipation capacity increases gradually until it reaches the peak. With the load increase, the mild steel dampers begin to break, the energy dissipation capacity decreases, until the mild steel damper is completely broken, the structure becomes completely self-centering rocking structure, almost no energy dissipation capacity.

Using the equivalent viscous damping ratio to evaluate the energy dissipation capacity of the structure, the variation law of equivalent viscous damping ratio with inter layer displacement is given in Figure 7. Overall, the equivalent viscous damping ratio first increase and then decrease with the increase of the layer displacement angle. The equivalent viscous damping ratio of the model reaches a peak value of 0.161 when the displacement angle of the layers is ; When the peak load is reached, the equivalent viscous damping ratio of the model is 0.144 ; When the ultimate load is reached, the equivalent viscous damping ratio of the model is 0.048 .

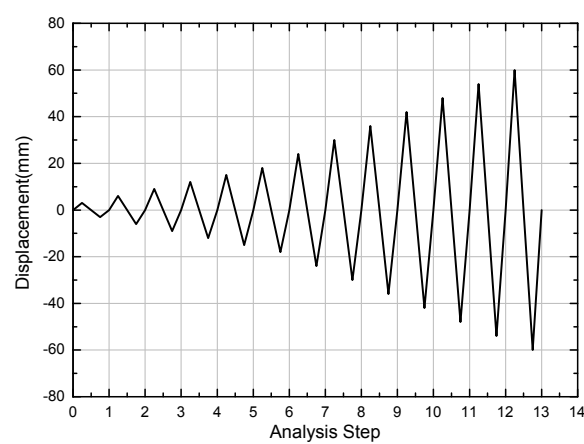

Figure 5. Cyclic horizontal load displacement loading system

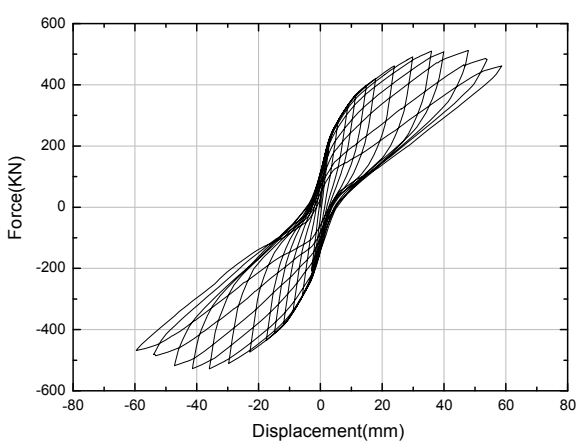

Figure 6. Hysteretic loops of model 


\subsection{Analysis of skeleton curve and bearing capacity}

The skeleton curve of the load - layer displacement is shown in Fig. 8. It can be seen from the figure that the model undergoes three stages: elastic stage, elastic stage, elastic- plastic stage and plastic destruct stage. The bearing capacity of the model reaches a peak value of when the value of the displacement angle of the layers is ( inter layer displacement ); The value of the bearing capacity of the model is when the value of the displacement angle of the layers is (inter layer displacement), this value of the bearing capacity is still not less than $85 \%$ of the peak bearing capacity, which means the structure with good deformation capacity.

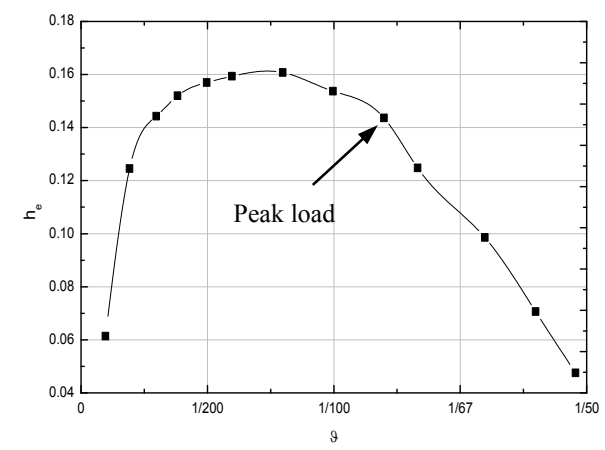

Figure 7. Equivalent viscous damping ratio

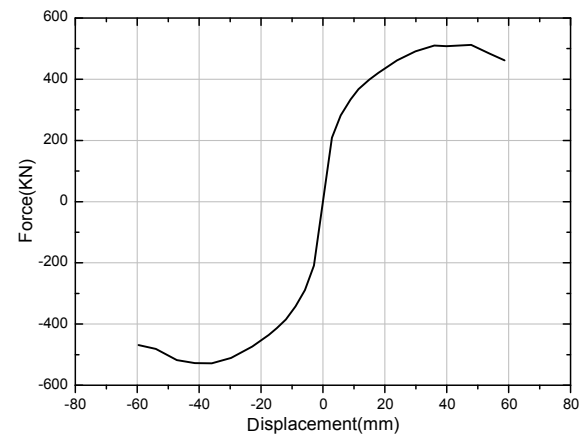

Figure 8. Skeleton curve of model

\section{Conclusion}

By the numerical simulation of the single span single frame model of the self-centering rocking wall embedded in steel frame structure system, the main results are as follows:

1) The self-centering function of the structure system mainly realized by the prestressed steel strands, energy dissipation function is mainly realized by mild steel damper.

2) The peak value of the structure bearing capacity is , corresponding layer displacement angle; the layer displacement angle corresponding limit value of the load is ; the peak value of the equivalent viscous damping ratio is 0.161 . The structural system has good energy dissipation capacity, load capacity and deformation capacity.

3) By rational arrangement, the plastic deformation of the structure in the large earthquake is concentrated in the energy dissipation device, the other parts of the structure are almost no residual deformation, and the structure system is basically restored to the position before loading after unloading, the plastic deformation of the mild steel dampers dissipate a large number of seismic energy, the structure has good energy dissipation and self-centering capacity.

\section{Reference}

1. Lv Xilin, Chen Yun, Mao Yuanjun. New Concept of Structural Seismic Design :Earthquake Resilient Structures [J]. Journal of Tongji University, 2011, 39(7): 941-948.

2. Kurama Y, Sause R, Pessiki S, et al. Lateral load behavior and seismic design of unbonded post- tensioned precast concrete walls [J] . ACI Structural Journal, 1999, 96(4):622-633.

3. Kurama Y C . Seismic design of unbonded post-tensioned precast concrete walls with supplemental viscous damping [J] .ACI Structural Journal, 2000, 97(4): 648- 658.

4. DANG Xiangliang, LU Xilin, ZHOU Yin. Experimental design and measured behavior analysis of self- centering shear walls with horizontal bottom slit [J]. Earthquake Engineering And Engineering Dynamics, 2014, 34(6):103-111. (in Chinese)

5. Code For Design of Concrete Structures( GB50010-2010)[S], Beijin: China Architecture \& Building Press, 2010 
6. Jia Yuanlin, Chen Shiming, Wang Xindi. Nonlinear finite element analysis of prestressed continuous steel- concrete composite beam with external tendons [ J ] Journal of Tongji University: Natural Science, 2011, 39 (9):1258- 1265. (in Chinese) 